\title{
Ensinar Antropologia em Tempos Sombrios
}

\author{
Sônia Weidner Maluf ${ }^{1}$ \\ ${ }^{1}$ Universidade Federal de Santa Catarina, Florianópolis, SC, Brasil
}

\section{Resumo}

Professoras e pesquisadoras em Antropologia ainda estão buscando compreender os efeitos que as recentes e rápidas transformações no cenário político e social do país produziram sobre o campo da educação básica, superior e de pós-graduação. O objetivo deste artigo é fazer uma reflexão sobre essas mudanças a partir da experiência concreta como docente de antropologia na graduação e na pós-graduação. Nas últimas décadas, viveu-se um processo de expansão da antropologia, com a criação de novos programas de pósgraduação, disseminação de disciplinas de antropologia em cursos de graduação, criação de graduações em antropologia. Ao mesmo tempo, as políticas de inclusão no ensino superior e na pós-graduação e a criação das licenciaturas interculturais indígenas, entre outras, produziram desafios metodológicos, pedagógicos, epistemológicos para o ensino de antropologia que vinham impulsionando a produção de novos paradigmas para o nosso campo. As mudanças radicais nas políticas educacionais para o ensino básico, superior e para a pós-graduação, desencadeadas a partir do processo que desembocou no golpe de 2016 e na instauração de um governo de extrema direita em janeiro de 2018, instauraram um novo e difícil cenário para a antropologia, para as ciências humanas e para o campo científico de modo geral. O ponto de partida para se pensar possíveis formas de resistência é conceber a sala de aula e o espaço educacional como lugares não apenas de transmissão do conhecimento, mas de reflexão crítica, dialógica e desenvolvimento de potências de transformação social.

Palavras-chave: Ensino de Antropologia. Universidade. Golpe de 2016. Pandemia de Covid-19.

\section{Teaching Anthropology in Dark Times}

\begin{abstract}
Anthropology professors and researchers are still trying to understand the effects that the recent and rapid changes in the country's political and social scenario have had on the field of education - basic, higher and postgraduate. The purpose of this article is to reflect on these changes from the concrete experience as an anthropology teacher in undergraduate and graduate courses. In the last decades, there has been a process of expansion of anthropology, with the creation of new graduate programs, the dissemination of anthropology disciplines in undergraduate courses, the creation of degrees in anthropology. At the same time, the inclusion policies in higher education and graduate studies, and the creation of intercultural indigenous degrees, among others, produced methodological, pedagogical and epistemological challenges for teaching anthropology that had been driving the production of new paradigms for our country. field. The radical changes in educational policies for basic and higher education and for postgraduate studies triggered by the process that led to the 2016 coup of State and the establishment of a far-right government in January 2018, introduced a new and difficult scenario for the anthropology, for the humanities and for the scientific field in general. The starting point for thinking about possible forms of resistance is to conceive the classroom and the educational space as places not only for the transmission of knowledge, but for critical, dialogical reflection and the development of potentials for social transformation.
\end{abstract}

Keywords: Teaching Anthropology. University. 2016 Coup. Covid-19 Pandemic. 


\section{Ensinar Antropologia em Tempos Sombrios}

$\mathrm{T}$

erça, 19 de agosto, foi a última aula do Curso Livre Antropologia saúde e cuidados em

tempos de pandemia, para o qual fui convidada a participar como docente junto com outros colegas do Departamento de Ciências Sociais da Universidade Federal da Paraíba (UFPB). O curso livre foi a forma que a universidade encontrou inicialmente para dar continuidade às atividades de ensino na graduação durante o isolamento social provocado pela Pandemia de Covid-19 $9^{1}$. Foram dez semanas de aulas, cada uma abordando um tema específico ligado ao assunto geral do curso e com uma metodologia planejada e em parte improvisada para garantir a viabilidade de uma aula dada de modo remoto, utilizando uma plataforma oferecida pela universidade, que possibilitava dois espaços e tempos virtuais para a aula: um momento chamado síncrono, ou seja, a aula em tempo real e com a participação de professoras e estudantes na plataforma de reunião virtual, com em torno de 60 estudantes participando por aula; e um momento assíncrono, em outro espaço virtual, em que as monitoras do curso, estudantes de mestrado e doutorado em antropologia, disponibilizam os textos, links e outros materiais como vídeos e podcasts, além dos vídeos das aulas síncronas².

Para todas nós, professoras e estudantes, foi uma experiência totalmente nova, difícil, cheia de inesperados e com momentos muito gratificantes. O que poderia ser uma idealização inicial de que bastaria transpor tudo o que fazíamos presencialmente em sala de aula para a tela do computador foi aos poucos se desmanchando. O tempo passado on-line, fazendo uma exposição ou assistindo, é muito mais cansativo e extenuante do que em uma sala de aula tradicional; a precariedade das conexões produz interrupções na audição; muitos estudantes não têm equipamentos nem serviços de internet viáveis para assistirem integralmente uma aula. Somado a tudo isso, percebemos que o problema não era apenas a questão técnica, metodológica e pedagógica do ensino remoto, mas o fato de que estávamos todas e todos mergulhados em uma situação global de possibilidade de exposição ao vírus, de isolamento, medo, demandas de cuidado de pessoas próximas (filhos, pais ou avós idosos), e até mesmo de adoecimento e morte de familiares, amigos e colegas. Para muitos estudantes, as dificuldades de conexão e de acesso às aulas nem

\footnotetext{
Participaram como docentes do curso Ednalva Neves, Luziana Silva, Márcia Longhi, Mónica Franch, Pedro Nascimento e eu. Tivemos em torno de 75 estudantes inscritas e uma média de frequência de 65 alunos por aula.

2 O ensino remoto, adotado pelas escolas e universidades brasileiras durante a pandemia de Covid-19, não deve ser confundido com o Ensino a Distância (EaD), este com metodologias, pedagogias e tecnologias específicas já bastante elaboradas e consolidadas. Esse alerta é importante para que não se conclua apressadamente que a pandemia inauguraria uma nova era de ensino a distância.
} 
eram o principal problema, mas encontrar meios de sobreviver, diante do fechamento de restaurantes universitários, restrições nas políticas de permanência e cortes de bolsas, perda de emprego, entre outros efeitos não só da pandemia, como também do acelerado processo de redução e de cortes nas políticas sociais, nos recursos para saúde e educação e da grave situação de crise social e política em que o país se encontra.

De certo modo, também em relação ao ensino, a pandemia amplificou uma situação que já vinha aparecendo no cotidiano de nossas atividades na universidade junto aos estudantes: a dificuldade de garantir condições isonômicas para todos em relação ao acesso às aulas, aos recursos de aprendizagem, livros, computadores, serviços de internet que possibilitassem pesquisas e consultas on-line de modo adequado e continuado. A grande inclusão no ensino superior e na pós-graduação vivenciada nas décadas anteriores precisou ser complementada com políticas de permanência que, ainda de forma muito incipiente e limitada, foram implementadas nas universidades públicas: bolsas, moradias estudantis, ampliação dos restaurantes universitários, espaços coletivos de estudo, auxílios variados. No entanto, foram essas políticas as que mais sofreram com os cortes e com a desestruturação do ensino público que se inicia com o golpe de 2016 e a aprovação da Emenda Constitucional n. 95, de dezembro do mesmo ano, que congelou os gastos com saúde e educação no país por 20 anos.

Junto com isso, as pós-graduações na área das ciências humanas e, particularmente na antropologia, têm sido alvo de uma política de cortes de bolsas e de recursos de custeio e de um processo de deslegitimação continuada por parte dos ministros que ocuparam o Ministério da Educação a partir de 2016.

Podemos dizer que o ensino de antropologia, em todos os níveis, tem vivido tempos sombrios, em que as bases mínimas de diálogo e de reconhecimento dentro do campo científico do país, que eram consideradas consolidadas ou em processo de fortalecimento, foram abaladas. Além disso, assistimos à implantação de políticas, através dos escassos editais e chamadas da CAPES e do CNPq, que, de forma geral, vão na contramão do que se entende por ciência e por campo científico no país, excluindo áreas inteiras da possibilidade de participarem dos editais, sob o critério absurdo de "áreas prioritárias", conforme discutirei mais adiante. Adicionado a isso, um movimento pelas hostes mais radicais e fundamentalistas do governo de ataque às ciências humanas ganhou grande visibilidade midiática, reforçado pelo ativismo anticiências humanas e, particularmente, antiantropologia do ex-ministro da educação Abraham Weintraub. Não à toa, a antropologia se tornou alvo prioritário desse ministro e, em um momento anterior, de deputados da chamada bancada ruralista do congresso nacional. O projeto de destituição dos povos indígenas de seus territórios para favorecer o avanço do garimpo ilegal e de outras atividades extrativas e de pecuária sobre as terras indígenas vem se reorganizando há mais tempo do que o atual governo, e tentou mostrar sua força na CPI da Funai, em cujo relatório se aponta uma lista de antropólogos e professores de antropologia, indigenistas e lideranças indígenas a serem denunciados e perseguidos pelo Estado. Essa mesma bancada hoje compõe a base de apoio do governo no congresso nacional e ocupa cargos nos ministérios e nos órgãos de fiscalização, como o Ibama e a Funai ${ }^{3}$

Uma das questões que emerge em relação ao avanço dos ruralistas, consolidado com a ocupação da Funai e do Ibama, entre outros órgãos e ministérios, por pessoas comprometidas com seus interesses, é a do exercício da profissão de 
Todos esses acontecimentos reconfiguram e colocam novos problemas ao ensino de antropologia. Os impactos que a conjuntura social e a política que vivemos no Brasil nos últimos anos trouxe para o campo da antropologia mostram que esse é um campo do conhecimento que não está imune aos movimentos da história e aos processos políticos, econômicos e sociais mais amplos.

É preciso pensar o campo do ensino de antropologia não só a partir dos movimentos e das dinâmicas internos à área, de sua expansão e da criação de novos cursos ou consolidação dos já existentes ou a partir da trajetória intrínseca à disciplina, mas levar em consideração os impactos das mudanças históricas e das conjunturas específicas no ensino $^{4}$. É difícil compreender a construção e a trajetória desse campo sem considerar fatores dessa história recente do país, em que o ensino de antropologia é afetado em diversas frentes: por meio das políticas de inclusão, nos conflitos relacionados às terras indígenas e na luta indígena pela demarcação e inviolabilidade de suas terras, nas políticas de reconhecimento e emergência de novos atores e sujeitos políticos reivindicando o acesso à universidade.

Em mais de três décadas de ensino na graduação e na pós-graduação, pude vivenciar e observar essas transformações de dupla entrada, internas e externas, no campo da antropologia brasileira. Parte de minha atuação como professora e pesquisadora aconteceu no Departamento de Comunicação da Universidade Federal de Santa Catarina (UFSC), onde atuei de 1986 a 1998, ano em que mudei para o Departamento de Antropologia da mesma universidade. E a partir de 1997, quando me vinculei ao Programa de PósGraduação em Antropologia (PPGAS) da UFSC.

É difícil, ao pensar em minha experiência de docência na antropologia, separar esses dois registros, o das demandas, dos processos e das dinâmicas internas ao campo e o das convocações e interpelações externas, dadas pelos acontecimentos extrínsecos como as políticas de financiamento, as políticas de educação e pesquisa, o maior ou menos investimento do Estado em ensino e pesquisa, os processos sociopolíticos e os debates nacionais - e mesmo internacionais.

É difícil separar as duas dimensões, na medida em que a dinâmica interna de crescimento e evolução do campo da antropologia acontece a partir de disputas e controvérsias teóricas, metodológicas, e até mesmo epistêmicas, que estão em conexão com o mundo extrauniversitário.

A seguir, trago algumas passagens de minha trajetória no ensino de antropologia que ilustram essa percepção. Nesses relatos, questões específicas de metodologias em sala de aula, modos de estruturação das diferentes teorias, abordagens dos conceitos centrais, dificuldades e obstáculos para a aprendizagem articulam dinâmicas internas ao crescimento do campo da antropologia no Brasil com os contextos políticos, sociais e econômicos do país e mesmo mundiais mais amplos.

antropólogo(a). Sem ser uma profissão reconhecida, com órgãos reguladores de seu exercício, é difícil garantir que os parâmetros e o código de ética do antropólogo definidos pela Associação Brasileira de Antropologia sejam respeitados por todos. Isso abriu a possibilidade para que grileiros e ruralistas interessados em ocupar as terras indígenas, ou que reivindicam a propriedade privada dessas terras, se utilizem do dispositivo do contralaudo.

4 Para uma apreensão histórica e de balanço do tema do ensino de antropologia, ver Durham e Cardoso (1961), Vega Sanabria (2005), Grossi, Tassinari e Rial (2006), Oliveira (2017), Vega Sanabria e Duarte (2019), entre outros. 


\section{Para Além das "Escolas"}

Grande parte do ensino dos clássicos antropológicos, em parte do ensino da antropologia contemporânea, é fundamentada na ideia de escolas de pensamento, que priorizam perspectivas e modelos explicativos ou interpretativos próprios e singulares, diferenciados, irredutíveis e mesmo impermeáveis à articulação com outras perspectivas. Essas divisões e categorizações certamente têm um papel na organização do processo de ensino da teoria antropológica, mas acabam em algumas situações sendo lidas como representação mecânica de um campo complexo de produção de conhecimento e que poderia ser representado de várias outras maneiras. Exercitar outros modos de ler as diferentes teorias, os conceitos, os paradigmas e os modelos explanatórios é um modo de fazer os estudantes (de graduação e de pós-graduação) aprenderem antropologia de modo reflexivo e crítico ${ }^{5}$. Essas diferentes formas de apreensão da teoria, quando justapostas e articuladas, podem trazer ao campo uma plasticidade e uma espessura que acaba sendo perdida nas classificações mais estanques de cada escola.

Muitas vezes as primeiras aulas das disciplinas de teoria, principalmente no mestrado e no doutorado, são marcadas pela exposição das angústias dos estudantes em relação às escolhas compulsórias que têm à frente, quanto às linhagens teóricas às quais se afiliarão na disciplina. Construir um caminho de apreensão dessas diversas correntes e "linhagens" teóricas e compreendê-las dentro da dinâmica de disputas e das linhas de força que atravessam e compõem o campo científico era um modo de ajudá-los a lidar com essa angústia, ou mesmo de se liberarem dela.

[...] minha abordagem foi sempre de pensar essas diversas correntes e linhagens com uma certa distância crítica, procurando configurar o campo científico, e dentro dele a antropologia, como campo de disputas e de linhas de força, em que eventualmente o caráter antagônico com que as teorias são apresentadas está ligado à construção de diferentes regimes de verdade no interior do campo antropológico, eventualmente mimetizando as ciências exatas ou naturais e abandonando o caráter reflexivo e dialógico das Ciências Humanas. Inspirada em Foucault, acredito que ensinar teoria antropológica é ensinar a reconhecer as diferentes teorias e suas especificidades, mas também a traçar genealogias e a compreender as articulações dos conceitos e teorias com seus respectivos contextos de formação. No caso da antropologia, o antagonismo e mesmo binarismo com que as teorias e os conceitos são colocados é frequente, e entre os estudantes é comum que se traduza em embates, muitas vezes paralisantes para quem está em pleno processo de formação na área. (MALUF, 2016, p. 34)

Reconhecer o caráter necessariamente artificial dos modelos que buscam representar a antropologia, que, mesmo sendo necessários, não impossibilitam outras matrizes de leitura da disciplina, acabou se tornando uma perspectiva fundamental em minha experiência de ensino.

\footnotetext{
Essa é uma questão que tem sido colocada por outros autores que pensam o ensino de antropologia ou de áreas afins. Claudia Mercedes Mora Cárdenas (IMS/UERJ), no Fórum “Antropologia e Saúde Coletiva: como ensinar Ciências Sociais e Humanas em Saúde na Contemporaneidade", da III Reunião de Antropologia da Saúde, realizada em 2019, sugere, por exemplo, que se pense a teoria mais a partir dos dilemas e dos conflitos do que a partir de escolas.
} 


\section{A Leitura a Contrapelo - Invenção e Reinvenção dos Clássicos e as Tensões da Crítica}

Nessa mesma perspectiva, fazer a genealogia dos clássicos ou daquelas obras canônicas da disciplina, e não apenas lê-los como verdades estabelecidas da disciplina, tornou-se um exercício muito interessante, não apenas na sala de aula. Acabei adotando esse procedimento em vários textos que publiquei, em que foi necessário produzir uma arqueologia da produção antropológica sobre o tema trabalhado. Parte desse exercício de leitura a contrapelo busca mostrar que a leitura estabelecida desses textos está “[...] dada pelo percurso que tiveram na disciplina" (MALUF, 2016, p. 35).

Essa arqueologia do conhecimento antropológico permite também que se entenda não apenas a produção do cânone estabelecido da disciplina, mas suas exclusões e apagamentos na produção das linhas mestras de cada escola ou de cada temática e campo de pesquisa. Certamente a antropologia feminista tem um papel fundamental nesse processo de revisão do cânone, não apenas a partir da crítica ao chamado male bias (viés masculino) das pesquisas e dos relatos etnográficos, mas por ser um exemplo que mostra a articulação entre movimentos internos à disciplina e interferências ou interpelações externas - no caso o próprio feminismo e os movimentos emancipatórios que emergiram no final dos anos de 1950 do século XX e ganharam maior visibilidade nos anos de 1970. O mesmo pode ser pensado em relação à crítica pós-colonial e ao modo como os descentramentos teóricos e conceituais que provoca atingem a antropologia. A contribuição da antropologia feminista para o que é a antropologia contemporânea é incontornável, apesar de essa compreensão não ser a perspectiva hegemônica, ainda voltada para a percepção internalista das transformações da disciplina. Como abordar o paradigma pós-estruturalista sem remeter às tensões em torno do sujeito moderno trazidas tanto pela crítica feminista e pós-colonial quanto pelas fricções provocadas pelo pensamento social crítico que emerge desses movimentos emancipatórios? A abordagem interdisciplinar de algumas temáticas acaba sendo incontornável. Como exemplo, cito dois dos temas que têm me ocupado em termos de ensino e pesquisa nos últimos anos: a antropologia da Pessoa, do Indivíduo e do Sujeito e a antropologia do Estado e das políticas públicas.

Da primeira vez em que ofereci o tópico especial Antropologia da Pessoa, no PPGAS da UFSC, em 1998, às sucessivas versões (Pessoa e Sujeitos Contemporâneos; Antropologia do Sujeito; Pessoa e Corporalidade; Corpo Sujeito e Poder; Teorias do Sujeito e Práticas e Teorias do Sujeito - esta última no PPGA/UFPB em 2019), esse duplo movimento entre repensar o cânone e produzir diálogos interdisciplinares a partir da antropologia foi se aprofundando. Essa dupla abordagem se desdobrava em dois módulos complementares com que a disciplina era dada: um primeiro módulo com os fundamentos da reflexão antropológica sobre as categorias de Pessoa e Indivíduo; um segundo módulo com as abordagens antropológicas contemporâneas e as diferentes teorias do sujeito, subjetividade e subjetivações vindas de outros campos do conhecimento. Essa estrutura de programa e plano de aula se repete em outras disciplinas optativas, como Antropologia, Estado e Políticas Públicas, com uma primeira parte abordando uma revisão da literatura antropológica sobre Estado, poder e políticas púbicas; uma problematização das relações 
da antropologia com o Estado e uma abordagem das teorias do Estado e das biopolíticas contemporâneas (trazendo na terceira parte da disciplina, o diálogo com alguns autores e autoras como Michel Foucault, Giorgio Agamben, Judith Butler, Gayatri Spivak, Nancy Fraser, Jean-Luc Nancy, Roberto Espósito, entre outros).

A seleção de autoras/es e textos a serem introduzidos aos estudantes é fundamental, no sentido de garantir uma política de representação nas referências que inclua autores e autoras mulheres, negros, latino-americanos, africanos, asiáticos, em geral não apenas "esquecidos" em favor das linhas centrais e estabelecidas, como invisibilizados e apagados pela reprodução de um tipo de eurocentrismo interno: preferência por autores europeus e norte-americanos em detrimento dos brasileiros e sul-americanos ou africanos; preferência por autores dos "centros" da antropologia brasileira em detrimento das produções dos próprios docentes do programa. Não defendo aqui que o critério da representatividade de gênero, étnica ou regional seja mais importante do que critérios estritamente acadêmicos. Penso que essa dicotomia é artificial. Reconhecer que a produção das "linhas mestras" da disciplina ou de seu "cânone" se dá também nas escolhas bibliográficas do Plano de Ensino ajuda a desnaturalizar esse mesmo cânone e a ofertar uma visão um tanto mais diversa e abrangente da disciplina. Percebi isso muito fortemente na disciplina Práticas e teorias do Sujeito, no PPGA da UFPB em 2019, quando ao final, na aula de avaliação do semestre, os/as estudantes comentaram sobre o quanto a diversidade dos autores e autoras trabalhados havia sido não apenas enriquecedora e elucidativa sobre o tema do curso, como os havia ajudado a ler de um modo mais reflexivo e crítico os clássicos da área - e inclusive de perceber sua contemporaneidade.

\section{A Experiência do Conceito}

Outro desafio colocado no ensino de antropologia é o trabalho com os conceitos, principalmente com os alunos de graduação, mas não apenas. A apreensão dos conceitos sempre exige um equilíbrio entre um grau de abstração, de imaginação, de articulação simbólica com outros conceitos e seus significados, e um grau de materialidade, que se desdobra em vários aspectos. Uma dimensão teórica e uma dimensão prática, empírica. Perceber ou assumir isso me ajudou muito para produzir a sala de aula, a aula, como um espaço não apenas de transmissão de conhecimento, mas também de produção de algum conhecimento, de envolver os estudantes não apenas na recepção, mas na produção de um pensamento próprio. Penso que essa dimensão teórico-prática deveria estar presente em todas as disciplinas: das mais práticas, como as de pesquisa de campo, por exemplo, às mais teóricas. Com as devidas diferenças e ênfases entre o que é figura e o que é fundo, ou, utilizando a imagem do símbolo taoísta, dos opostos que se contêm mutuamente. Situações empíricas observadas em um episódio de pesquisa ou em exemplos trazidos pelos estudantes podem ser analisadas e compreendidas por meio da correlação com conceitos e teorias - eventualmente acionando-se diferentes perspectivas teóricas para abordar a mesma situação. Do mesmo modo, uma teoria, modelo analítico ou um conceito podem ser compreendidos e mesmo colocados sob fricção através de relatos de situações empíricas. A leitura de boas etnografias - que articule de modo competente 
o material etnográfico com boas análises e recortes teóricos, cumpre parcialmente esse objetivo. Digo parcialmente, porque considero importante que os estudantes possam experimentar operações similares em sala de aula com observações e exemplos trazidos por eles próprios. É difícil descrever como isso é feito concretamente no espaço limitado de um artigo cuja abordagem do tema é mais abrangente, mas certamente o trabalho com exemplos concretos, de pesquisas de campo ou trazidos por eles a partir de suas experiências e observações pessoais é um momento fundamental desse aprendizado ${ }^{6}$.

Um exemplo foi uma experiência na disciplina de Cultura Brasileira, para a graduação ${ }^{7}$, em que levei diferentes imagens do uso da bandeira do Brasil. Uma foto do desfile militar do 7 de Setembro; uma foto em preto e branco de uma manifestação estudantil em que a estudante se protege com uma bandeira do Brasil de papel, quando o batalhão da Polícia Militar se aproxima, e outras fotos em que a bandeira aparecia em situações diferentes. E pedi para eles discutirem a questão da Nação e de seus símbolos a partir dessas imagens ${ }^{8}$. O objetivo desse exercício foi não somente apreender a pensar o símbolo dentro do seu contexto específico, mas de pensar a fricção entre símbolo e prática social, e como a prática social produz mudanças não apenas nos símbolos, mas nos conceitos (que são outra forma de representação - de uma ideia, de um fenômeno). Até chegarmos à noção do conceito como campo de disputas e da teoria como espaço de friç̧ão, sobretudo a teoria etnográfica, em que os conceitos e os modelos estão permanentemente sendo colocados em questão pela experiência e pelo estar no mundo. Como já escrevi em outro momento, o trabalho etnográfico concreto, no "campo", é um dos princípios elementares da prática e do conhecimento antropológicos e o que marca sua diferença com outras ciências afins. Um dos grandes desafios do ensino de antropologia é mostrar e demonstrar, ou fazê-los viver a experiência de que, entre o mundo e a representação do mundo, existe um caminho do meio (WAGNER, 2010).

Dois conceitos com os quais trabalhei tanto em minhas pesquisas e publicações como na sala de aula ajudam a exemplificar de modo mais detalhado essa questão. O primeiro é o conceito de sujeito, a partir das diferentes teorias que contribuíram para sua formulação, incluindo as teorias sociais críticas que provocaram uma rasura do conceito. Estou aqui utilizando uma expressão adotada por Stuart Hall (2000), em sua discussão sobre identidade, em que admite as críticas e limitações do conceito, propondo que, apesar dessas críticas, ele mantém sua utilidade analítica, desde que reconhecida essa história crítica, ou seja, como um conceito rasurado. Hall também questiona a intenção de busca de conceitos perfeitamente adaptados aos objetos que buscamos analisar. A ideia da rasura e do desencaixe ou o não encaixe perfeito entre conceito e realidade

\footnotetext{
6 Os próprios estudantes costumam ilustrar e mesmo produzir argumentos em torno dos textos e debates de sala de aula com exemplos trazidos de sua própria experiência ou de fatos extraídos das mídias e das redes sociais. Percebo aí um duplo movimento entre, de um lado, o esforço de compreensão de formulações teóricas mais abstratas trazendo-as para a proximidade da experiência e do cotidiano, e, de outro, o desejo ou disposição de elaborar e compreender essas mesmas situações trazidas para a sala de aula com os instrumentos do conhecimento antropológico.

7 Disciplina que ofereci do final dos anos de 1990 ao início dos anos 2000.

8 Uma referência posterior para essa discussão dos símbolos nacionais, e que foi introduzida em outras disciplinas que ofereci é o texto Quem canta o Estado-Nação em que Judith Butler e Gaiatri Spivak analisam a apropriação do hino nacional dos EUA, cantado em espanhol pelos imigrantes sem documento durante o governo de George W. Bush. (BUTLER; SPIVAK, 2009).
} 
observada, da fricção entre a teoria e o mundo observado, é central para a perspectiva que desenvolvo neste artigo.

No caso de uma antropologia do sujeito, que busco discutir em diálogo com a apreensão antropológica da pessoa e do indivíduo, propondo que é um conceito útil para ir além da perspectiva da representação social, à qual se associa mais fortemente a noção de Pessoa, cabe colocar esse conceito também sob tensão. Essa tensão é dada, de um lado, na história crítica do conceito de sujeito, a partir das teorias sociais contemporâneas, entre elas o feminismo, a psicanálise, os estudos pós e decoloniais, as análises foucaultianas e a filosofia da diferença, para as quais o sujeito como ente unificado substantivo, anterior à própria experiência no mundo ou à sua produção no interior das relações sociais, é uma ficção. Um descentramento que de certo modo já havia sido provocado pela antropologia quando relativiza a universalidade do sujeito da razão moderno. E de outro, no modo como novos movimentos emancipatórios se produzem na emergência de novos sujeitos políticos advindos da luta anticolonial, do feminismo e dos movimentos de mulheres emancipatórios, da luta antirracista, da luta indígena. No entanto, ao mesmo tempo que rasurado por toda essa crítica, e de modos diferentes, o conceito de sujeito, principalmente tomado como processo em curso através de diferentes regimes de subjetivação, mantém sua utilidade para a análise social - desde que tomado com suas rasuras e com a história crítica e política que carrega em sua trajetória.

Trabalhar essa perspectiva do conceito em sala de aula requer um trabalho em dois planos complementares: o plano da crítica interna ou da abstração crítica do conceito, dada pelas teorias e suas convergências e divergências em torno dele; e o plano da contingência empírica, em que o conceito é confrontado a situações etnográficas, relatos de pesquisa de campo, ou mesmo de exemplos trazidos pelos estudantes. Parafraseando Luiz Eduardo Soares (1994), também a indisciplina precisa ser praticada com rigor.

\section{Eu e Eles/as - Nós - em Sala De Aula}

Existe uma dimensão etnográfica de se estar em sala de aula. Não no sentido de fazer uma etnografia daquele espaço social, mas no sentido da relação que se estabelece entre as pessoas. Eu sempre me pergunto, quando inicio um semestre novo: quem são essas pessoas aqui? Com quem estou me relacionando durante todo este semestre? Como produzir um diálogo entre nós, os textos e os autores que vamos abordar? Como vou tornar viável essa relação durante o semestre e chegar ao final e poder avaliar que algo interessante se produziu aqui? Penso que essa é a grande questão. Como medir isso? Chamada, trabalhos, fichamentos, provas? Talvez eu preferisse não fazer chamada, não fazer prova, avaliação sempre foi o pior momento do semestre para mim, mas esses instrumentos são necessários para garantir a impessoalidade e um mínimo denominador comum do qual se possa partir inclusive para avaliar situações específicas e casos ou

dificuldades individuais. É preciso ter critérios e tudo isso deve estar previsto e descrito no plano de aula. Eu costumo colocar tudo no plano, inclusive a programação aula a aula, a estrutura dos seminários, as formas de avaliação. 
É nessas perguntas que começo a perceber as mudanças no perfil dos estudantes. Com as políticas de ação afirmativa e as cotas para estudantes de escolas públicas, as cotas raciais e étnicas, as vagas destinadas a indígenas e quilombolas, os estudantes que chegam na universidade, principalmente os vindos de escolas públicas, dispõem de menos recursos econômicos, muitos são também trabalhadores, que enfrentaram e enfrentam dificuldades para acesso a livros, computadores, aprendizado de outras línguas. Esses são fatores que precisam ser levados em consideração e, em geral, são muito mal enfrentados. Um exemplo é a questão do aprendizado de língua estrangeira. As seleções para mestrado e doutorado costumam exigir o domínio de uma ou duas línguas estrangeiras. Em geral, no nosso campo, o inglês e o francês. Apenas mais recentemente alguns programas passaram a aceitar o espanhol como segunda língua estrangeira. Isso cria uma barreira enorme para estudantes vindos de classes populares, da periferia, da escola pública. Para um estudante chegar na pós-graduação conseguindo ler e entender bem um texto em inglês e em francês, ele deve ter tido a oportunidade de estudar essas línguas, o que no Brasil em geral é feito em escolas e em cursos particulares. Isso já determina um recorte de classe evidente nos processos de seleção. Essa situação se tornou ainda mais importante com as políticas de ação afirmativa, em que um manancial enorme de estudantes que finalmente conseguiu entrar na graduação quer continuar estudando, fazer mestrado, doutorado, mas tendo que enfrentar as mesmas exigências, já difíceis de serem atendidas pelos estudantes antes das cotas. O grande equívoco é creditar essas dificuldades aos estudantes e não ao sistema de ensino, à falta de uma política de tradução para o português e mesmo à falta de entendimento de que, na realidade da educação brasileira, a pós-graduação deve também proporcionar acesso ao aprendizado de outras línguas. Mas, para isso, para uma formação mais completa, integral, é necessário que haja dedicação exclusiva. E aí entramos em outra questão que são as bolsas de estudo, não apenas se elas contemplam todos os que têm necessidade, mas se o valor delas garante a sobrevivência e a possibilidade de dedicação integral aos estudos. Em relação a acesso aos livros e à bibliografia exigida pelas disciplinas, sua disponibilização nas bibliotecas é fundamental, não apenas a literatura que consta nas ementas básicas das disciplinas.

O acesso à literatura antropológica clássica e contemporânea, estrangeira e brasileira, é fundamental para se produzir na aprendizagem um pensamento crítico com uma compreensão mais densa e reflexiva sobre as teorias antropológicas, os paradigmas analíticos, os principais debates e controvérsias - uma reflexividade necessária para que os estudantes e os futuros pesquisadores e pesquisadoras em formação não fiquem na posição de espectadores dos grandes debates dentro do campo. 


\section{As Novas Caras da Universidade}

Em 2013, fui convidada pela reitoria da Universidade Federal de Santa Catarina a dar a aula magna para os calouros ingressantes no segundo semestre. Falar da universidade naquele momento, tema que escolhi para a aula magna, era necessariamente falar das importantes mudanças trazidas nos anos recentes ligadas às políticas de inclusão no ensino superior, em especial sobre as ações afirmativas e a expansão da universidade pública, com a ampliação das vagas e de universidades. A política de ações afirmativas, e, em especial, as cotas para negros e pardos e indígenas nas graduações e em diversos cursos de mestrado e doutorado, trouxe mudanças enormes não apenas para as universidades, mas os efeitos dessa inclusão, mesmo que parcial, para a sociedade se fizeram sentir muito rapidamente. Em 2013, com quase 18 universidades novas inauguradas, novos campi e institutos federais, a universidade pública brasileira discutia o aprimoramento e a ampliação das políticas de inclusão e, principalmente, a necessidade de mais e melhores políticas de permanência dos estudantes advindos das escolas públicas e das políticas de ação afirmativa. As políticas de inclusão no ensino superior significaram uma das mais importantes mudanças vividas na universidade brasileira e fora dela, principalmente pelos efeitos da entrada daqueles que desde a criação da instituição universitária no país permaneceram excluídos. A história do ensino superior no Brasil mostra não apenas o caráter tardio de sua criação no país como a implementação de uma política de exclusão das classes populares sistemática e deliberada, em especial da população negra e parda. No período colonial, apenas os filhos homens da elite branca podiam cursar ensino superior, e isso só poderia ser feito fora do Brasil, em especial em Portugal, na Universidade de Coimbra. A universidade brasileira, quando surge, já surge sob o signo da exclusão dos negros, das mulheres, dos indígenas e dos pobres e trabalhadores. O que percebemos, após alguns anos de políticas de ação afirmativa, é que não eram apenas estratos e segmentos enormes da população brasileira que estavam fora das universidades, mas toda uma experiência social e cultural, toda uma realidade social do país, que havia permanecido excluída da produção e da transmissão de conhecimento. Para o campo das ciências humanas, das letras e das artes, e em especial da antropologia, isso tem um peso enorme, e vai se fazer sentir de maneira contundente quando negros, pardos, indígenas, começam a sentar nas cadeiras da sala de aula. Os clássicos "outros" da produção antropológica brasileira agora estão ali, não mais na terceira pessoa de um "eles" distante e ausente, mas como um "nós" afirmativo e crítico. A universidade com sua histórica "cara branca", como definiu o antropólogo José Jorge de Carvalho, aquela em que se contava nos dedos os estudantes e os professores e professoras negras, e ainda menos os indígenas, começava a mudar de cara. A inclusão deveria se estender a todas as pessoas que precisaram também produzir um manto de invisibilidade, em uma universidade não apenas historicamente branca, mas também classista, machista, heteronormativa, capacitista e preconceituosa em suas estruturas. O enfrentamento a essas formas de exclusão e preconceito passava a ocupar as instâncias oficiais, reuniões, conselhos, portarias, editais de seleção nos programas de pós-graduação, no sentido de produzir dispositivos para confrontar esses preconceitos e exclusões. Entre eles, as políticas de permanência, como bolsas, ampliação das moradias estudantis, restaurantes 
universitários, obrigatoriedade do uso do nome social de pessoas trans, segurança para as mulheres e pessoas LGBTQIA+ dentro dos campi, entre outras medidas.

Esses processos também afetaram o ensino de antropologia, tanto na graduação quanto na pós-graduação. O perfil das turmas de ingressantes começou a mudar muito rapidamente, mudanças nem sempre acompanhadas de uma reflexão sobre a necessidade de adaptar currículos de curso, planos de aula e mesmo metodologias de ensino. Não se tratava apenas de acolher na sala de aula toda uma experiência social que havia ficado de fora, mas de permitir que a presença dessas experiências sociais modificasse conteúdos e metodologias de ensino e de transmissão do conhecimento antropológico.

Novas metodologias são pensadas e começam a ser experimentadas, como a pedagogia da alternância, utilizada nos cursos de Licenciatura Intercultural Indígena e de Educação no Campo, da UFSC. Nessa metodologia, alternam-se um período de aulas presenciais na universidade e um período nos locais de moradia dos estudantes - indígenas, em suas terras; camponeses e agricultores, junto a suas cidades e comunidades. No caso dos estudantes indígenas, houve também a necessidade de um espaço dentro da universidade para abrigar as crianças que acompanham mães e pais estudantes. Esse é apenas um exemplo em um universo de vivências, dificuldades, aprendizados também para quem ensinava ou fazia a gestão desses novos processos.

Por mais que a nova realidade trazida pelas políticas de ação afirmativa e pelos novos sujeitos que passam a frequentar o campus e a exercer seu pleno direito tenha produzido grandes desafios aos velhos e já consolidados sistemas de ensino e de formação, ela representou e ainda representa um momento de grande ebulição política, ética e epistêmica. Com todas as limitações das políticas de inclusão, a carência de políticas de permanência efetivas, a escassez de recursos para efetivar algumas medidas estruturais necessárias, a universidade, e junto com ela o ensino de antropologia, estavam vivendo uma grande e bem-vinda transformação. Em pouco tempo, a resposta daqueles que preferiam que a universidade e a sociedade brasileira tivessem ido por um caminho oposto seria dada.

\section{Novos Velhos Tempos Sombrios}

O processo que irrompe no país com o golpe jurídico-parlamentar de 2016 desencadeia muito rapidamente uma série de medidas que não apenas modificam como colocam limites e mesmo extinguem políticas públicas e sociais, instituições, dispositivos de controle e fundamentalmente transformam a narrativa sobre para onde vai o país. A velocidade e a agressividade com que essas mudanças são feitas lembram o modo de operar da doutrina militar do shock and awe, choque e pavor, ou doutrina do domínio rápido. Mal assumiu o vice Michel Temer, um novo gabinete de ministros foi composto, em grande parte pelos descontentes com a pauta distributiva, de inclusão, de direitos e com as políticas sociais dos governos Lula e Dilma. Ruralistas, fundamentalistas evangélicos, armamentistas, privatistas ligados a empresas e corporações no campo da saúde e da educação passam a ocupar esses ministérios. Ainda no ano de 2016, após o afastamento de Dilma, várias políticas sociais foram modificadas ou mesmo canceladas, 
na saúde, na educação, nas relações de trabalho, retrocedendo, como nesse último caso, não a antes dos governos do PT ou aos anos de ditadura militar, mas aos anos de 1940, quando foi sancionada a Consolidação das Leis do Trabalho (CLT, 1943). A estratégia militar do shock and awe, utilizada na guerra do Iraque com a morte de civis, mulheres, crianças, destruindo formas e espaços de vida de uma população inteira, tornou-se uma estratégia política de "arrasa território" nas políticas sociais e na própria estrutura do Estado, mas também nos territórios morais, afetivos e cognitivos, na possibilidade mesmo de compreensão e, consequentemente, de ação ou de reação. Juntamente com as medidas políticas tomadas pelo governo federal, um modo político de operar, com fortes tintas fascistas, se dissemina pelo país, através de violência física e simbólica contra adversários políticos, uso do poder discricionário para decidir quem tem e quem não tem direitos, que se torna muito evidente também no modo de operar do campo jurídico, instauração de uma política do medo e perseguição aos opositores.

No campo da educação, uma medida teve efeitos contundentes na escola básica e no ensino de ciências sociais na graduação: a eliminação da obrigatoriedade do ensino de sociologia na escola básica. Tornada obrigatória, juntamente com filosofia, nas três séries do ensino médio em escolas públicas e privadas em lei sancionada em junho de 2008, 37 anos depois de sua substituição pela disciplina de Moral e Cívica em 1971, mais uma vez a eliminação da obrigatoriedade do ensino de ciências sociais ocorre em paralelo com o surgimento de um governo autoritário e com o colapso da democracia. Incluída e articulada com um grande pacote de "flexibilização" do ensino médio, denominada pelos especialistas e pesquisadores em educação de contrarreforma do ensino médio, o efeito dessa medida sobre o ensino de graduação foi desestruturador, levando em consideração que as licenciaturas na área estavam em processo de expansão, qualificação e atração de novos estudantes, dispostos a construir uma carreira como professores e professoras de sociologia no ensino médio. Esse impacto se estendeu também para os mestrados e doutorados, cujos egressos cada vez mais estavam optando pelo magistério no ensino médio.

Outra dimensão em que a educação básica e superior foi profundamente afetada foi o crescimento do espaço do projeto com o nome fantasia de "Escola sem partido", que instiga a denúncia de professores e busca instituir censura e controle sobre o ensino em todos os níveis. O objetivo desse projeto é instaurar nas escolas e universidades um ambiente de perseguição e repressão, além de estimular a delação e a violência na sala de aula. O alvo predileto dos projetos de amordaçamento da escola é a temática de gênero e de educação sexual nas escolas. Apesar de aprovado em algumas câmaras municipais, o Supremo Tribunal Federal derrubou sucessivamente as leis aprovadas, declarando-as inconstitucionais. Paralelamente, os consecutivos ministros da educação dos governos Temer e Bolsonaro, além de defenderem esse projeto, iniciaram uma verdadeira cruzada contra as ciências humanas, em particular a antropologia. As tentativas de deslegitimar e de retirar a importância do ensino e da pesquisa nas humanas chegou aos editais de pesquisa do CNPq, ligado ao Ministério da Ciência, Tecnologia, Inovação e Comunicações (MCTIC), que produziram uma distorção no sistema de pesquisa do país ao eleger "áreas 
prioritárias" em editais e chamadas de auxílio e bolsas ${ }^{9}$. As ciências humanas ficaram de fora, por exemplo, do edital de bolsas de Iniciação Científica de abril de 2020 do CNPq. Retirar dos estudantes de graduação a possibilidade de iniciação à pesquisa significa cortar pela raiz a formação de novos pesquisadores e pesquisadoras, medida que terá consequências pesadas sobre a grande área de ciências humanas nos próximos anos e na formação de novos e novas pesquisadoras.

Várias outras medidas foram tomadas, incluindo ações autoritárias por parte do governo, como a tentativa do ministro da educação Mendonça Filho de censurar a disciplina sobre "O golpe de 2016 e o futuro da democracia"10, ofertada na Universidade de Brasília. Ele acabou recuando depois da repercussão negativa da tentativa de censura e da reação das universidades, que criaram dezenas de cursos similares em todo o Brasil. Antes dos cursos, muitos eventos, mobilizações, mesas redondas, seminários, conferências e reuniões já estavam acontecendo nos campi universitários em todo o Brasil. Na UFSC, foi criado o movimento UFSC Contra o Golpe e pela Democracia, que hoje reúne um grande número de docentes, técnicos e estudantes na Frente Democrática da UFSC, criada diante da ameaça real que a eleição de Jair Bolsonaro representou para a universidade pública. E o mesmo ocorreu em quase todas as universidades do país.

As mudanças radicais nas políticas educacionais para o ensino básico, superior e para a pós-graduação desencadeadas a partir do golpe de 2016 e com a instauração de um governo de extrema direita em janeiro de 2019 abriram um novo e difícil cenário para a antropologia, para as ciências humanas e para o campo científico de modo geral. Se a agenda de debates sobre o futuro da universidade de antes de 2016 discutia sobre como e para onde expandir e democratizar o ensino universitário, sobre como garantir políticas de permanência e inclusão além das ações afirmativas, sobre a necessidade de expansão e de revisão do valor das bolsas, de mais moradias estudantis, de estreitar a relação entre a universidade e a comunidade e a cidade, a partir de 2016, a luta se voltou contra o teto de gastos, contra os cortes que aumentam a cada novo orçamento anual do governo, e buscando resistir aos sucessivos processos de intervenção nas universidades com a designação de reitores não escolhidos pela comunidade universitária. Se, nas últimas décadas, as ciências sociais e a antropologia em particular voltaram-se para pensar as epistemologias do Sul, para refletir sobre os impactos sociais e contribuições da pesquisa para a melhoria da vida e das políticas sociais, a buscar formas de transformar os modos de ensino e de transmissão do conhecimento, levando em consideração a realidade de vida dos estudantes e de suas comunidades de origem, hoje estamos na defensiva e lutando pelo reconhecimento da necessidade da existência das Ciências Humanas e da Antropologia.

\footnotetext{
Os editais e chamadas anteriores tinham em geral como política a definição de demandas espontâneas e de demandas induzidas, estas em torno de temáticas e setores da pesquisa, mas sem restrição ou priorização de áreas do conhecimento específicas. Foi isso que permitiu, por exemplo, que grupos e redes de pesquisa da área de Ciências Humanas pudessem participar de editais como os dos INCTs.

10 Disciplina proposta pelo professor Luis Felipe Miguel do Instituto de Ciência Política da UnB.
} 


\section{Tempos Pandêmicos}

É durante o agravamento desse quadro político, com as crescentes intervenções nas reitorias das universidades, o corte de verbas, de bolsas, e a paralisia das contratações, que se instala a pandemia de Covid-19, em março de 2020, mês em que se inicia o calendário letivo anual nas escolas e nas universidades.

A suspensão do calendário após duas semanas de aulas, as medidas de isolamento social tomadas por prefeituras e governos de estado, mas sem o apoio do governo federal, trouxeram novas questões para a pesquisa e o ensino de antropologia. Muitos estudantes que estavam em pesquisa de campo, ou iniciariam suas pesquisas, foram obrigados a interromper suas atividades e retornar ou sair do campo, não apenas em territórios indígenas, quilombolas, ou regiões rurais, mas também as pesquisas feitas em espaços urbanos foram profundamente afetadas. Sem saber a extensão da pandemia e até quando duraria, uma paralisia inicial tomou conta das instituições de ensino. Alguns simplesmente tentaram continuar as aulas on-line, outros suspenderam as atividades presenciais enquanto encontravam formas de dar continuidade às atividades, principalmente as aulas de outro modo. As universidades se engajaram em um debate sobre ensino remoto, ensino a distância, inclusão digital e a possibilidade de os estudantes, principalmente aqueles sem recursos, sem computadores e sem serviços de internet razoáveis, acompanharem as aulas. Algumas secretarias estaduais e municipais de educação buscaram dispositivos para viabilizar o ensino remoto, como a distribuição de computadores, pagamento de serviços de dados e até mesmo a distribuição de cestas básicas, com o intuito de garantir a alimentação dos estudantes que dependiam da merenda escolar. Mas essas iniciativas foram esparsas e muitas vezes insuficientes diante da falta de uma política nacional de enfrentamento. O próprio ministro da educação colocou-se como contrário ao isolamento social e ao cancelamento das aulas durante a pandemia, reproduzindo a política geral do governo federal de negação da gravidade da pandemia.

Com todas essas dificuldades, as escolas e as universidades continuaram funcionando, mesmo que algumas inicialmente sem as aulas regulares com os componentes curriculares formais. A UFPB optou nos primeiros três meses de pandemia, no caso da graduação, pelos chamados Cursos Livres, com a possibilidade, mas não obrigatoriedade, de matrícula por parte dos estudantes. A experiência dos cursos livres ajudou a compor uma série de aspectos necessários para um ensino remoto regular: uma duração menor das aulas; tempo maior de preparação para os docentes (na medida em que precisaram adaptar seus planos a novas metodologias e tecnologias); gravação das aulas e disponibilização nas plataformas de ensino, para que estudantes com dificuldade de acesso à aula síncrona pudessem acessá-la em outro momento; trabalho com outros materiais além dos textos e da bibliografia já definida, como textos mais curtos, material de jornal, vídeos, podcasts, entre outros dispositivos. Mais importante do que a preocupação em oferecer os componentes curriculares formais, parece necessário garantir um espaço de aprendizado e reflexividade para os estudantes em que a sala de aula remota possa fornecer elementos para enfrentarem a pandemia e seus efeitos sociais e subjetivos. Torna-se mais forte ainda a necessidade de acolher a realidade dos estudantes dentro da sala de aula e de fornecer instrumentos para que essa realidade seja compreendida 
e elaborada de modo mais consistente, possibilitando instrumentos de resistência e de ação para enfrentar as enormes dificuldades vividas pela população de baixa renda, jogada no desemprego e na informalidade do mercado de trabalho.

A pandemia também amplificou o debate em torno da ciência e da pesquisa científica. De um lado, a exacerbação de um discurso negacionista e anticientífico por parte do governo federal e dos políticos que apoiam o atual presidente, e que se dissemina pelas redes sociais e em alguns veículos de imprensa; de outro, o fato de que a ciência nunca esteve tanto em pauta nas mídias e junto à população, nunca cientistas e pesquisadores estiveram tão presentes em programas de entrevistas e reportagens, eventualmente com atualizações diárias sobre pesquisas, dados epidemiológicos, etc. As ciências sociais e a antropologia ocupam um lugar muito delicado diante dessa polarização entre um governo anticiência de um lado e de outro a defesa de uma concepção de ciência em algumas situações bastante reducionista e excludente, que acaba não reconhecendo a importância da pesquisa nas ciências humanas para o enfrentamento à pandemia. A antropologia tem um longo caminho já percorrido na pesquisa sobre epidemias, e não foi por acaso que no Brasil a resposta dada pela área e pelo campo mais amplo das ciências sociais foi extremamente vigorosa: os boletins da Associação Nacional de Pós-Graduação e Pesquisa em Ciências Sociais (ANPOCS), com textos curtos e bastante programáticos em torno de temas ligados à pandemia; os sites e plataformas criados para compartilhar análises, dados de campo e alguns voltados para a extensão e o apoio às comunidades em situação de grande vulnerabilidade e precariedade social. O grande aprendizado, que inspiram todas essas iniciativas, é que um acontecimento epidemiológico como a pandemia é também um acontecimento fundamentalmente social, produz impactos sociais, os modos de enfrentamento tem determinantes sociais, econômicos e culturais importantes e que, por mais que se pensem protocolos, se pesquisem medicamentos e vacinas e se adotem medidas sanitárias corretas, sem um conhecimento das populações, das comunidades e dos sujeitos para quem esses protocolos, medicamentos e medidas foram pensados, eles dificilmente cumprirão seus objetivos - estarão, como já se viu em relação a outras epidemias ou situações de catástrofe, fadados ao fracasso parcial ou total.

Ensinar antropologia é também ensinar sobre a importância, a necessidade e a contribuição que o conhecimento antropológico pode trazer em situações como a que estamos vivendo em nível planetário com a pandemia de Covid-19.

No Brasil, a pandemia é vivida em meio a uma conjuntura política e econômica que agrava em muito a situação das comunidades e das populações com quem pesquisamos. Os futuros possíveis dessa crise não estão totalmente definidos. Os presságios são muitos e nos convocam a pensar em como exercitar a imaginação antropológica não apenas em nossos artigos e palestras, mas também na sala de aula. 


\section{Considerações Finais}

Na tela do computador, o quadriculado mostra os rostos dos estudantes, fotos e avatares, a letra do primeiro nome. Alguns preferem não abrir o vídeo, alguns colocam perguntas e comentários no chat, outros abrem o microfone e trazem suas dúvidas e reflexões. O silêncio, no encontro remoto, é mais contundente, mais difícil de lidar, mas sei que será breve, então aguardo que liguem o microfone e se expressem. O tempo da reflexão ainda se confunde com o tempo da experiência, dos afetos, dos medos, das angústias e das tristezas que nos envolvem nesses tempos difíceis. A experiência dramática dos tempos sombrios dificulta e exige ao mesmo tempo sua representação e compreensão. A experiência da crise e da catástrofe dificulta nossa capacidade de compreensão e de representação, mas é ela também que nos move e nos leva a querer falar dela, representá-la, é o que dá sentido à representação e ao conhecimento. Estamos aqui - e agora - num momento único, para, em sala de aula, transformar em aprendizado o dilema central da relação entre experiência e conhecimento: como "não desistir do conhecimento sem trair a natureza do vivido" (NESTROVSKI; SELIGMANN-SILVA, 2000). Em outra formulação: como manter a potência do vivido sem abdicar da necessidade de conhecimento e de uma representação plausível. Se admitirmos que o que esvazia a experiência é a indiferença e a insensibilidade diante dela, muitas vezes provocadas por sua superexposição (NESTROVSKI, 2000), apanhar a experiência em forma representação - e de conhecimento - é um modo de confrontar-se à indiferença e ir além das representações fragmentárias e parciais de sua apreensão imediata ou de sua banalização. É, por sua vez, por estar permanentemente sob o crivo do mundo - e da experiência - que o conhecimento antropológico encontra a singularidade e a especificidade, a qualidade própria, de sua produção e transmissão.

\section{Agradecimentos}

Agradeço pelo convite das organizadoras do dossiê e pelo estímulo reiterado de Ari José Sartori para que eu escrevesse este artigo, desde a entrevista que fez comigo em junho de 2017.

\section{Referências}

BUTLER, Judith; SPIVAK, Gayatri Chakravorty. Quien le canta al Estado-Nación? Lenguaje, política pertenencia. Buenos Aires: Paidós, 2009.

DURHAM, Eunice R.; CARDOSO, Ruth C. L. O ensino da antropologia no Brasil. Revista de Antropologia, São Paulo, v. 9, n. 1-2, 91-108, 1961.

GROSSI, Miriam; TASSINARI, Antonella; RIAL, Carmen. (org.). Ensino de antropologia no Brasil: formação, práticas disciplinares e além-fronteiras. Blumenau: Nova Letra, 2006.

HALL, Stuart. Quem precisa da identidade? In: TADEU DA SILVA, Tomaz (org.). Identidade e diferença: a perspectiva dos estudos culturais. Petrópolis, Vozes, 2000. p. 103-133. 
MALUF, S. W. Memorial de atividades acadêmicas (MMA) para avaliação com finalidade de progressão para classe " $E^{\prime}$ do Magistério Superior (Titular de carreira). Florianópolis: UFSC, 2016.

NESTROVSKI, Arthur; SELIGMANN-SILVA, Márcio. Apresentação. In: NESTROVSKI, Arthur; SELIGMANN-SILVA, Márcio (org.). Catástrofe e representação. São Paulo: Escuta, 2000. p. 7-12.

NESTROVSKI, Arthur. Vozes de crianças. In: NESTROVSKI, Arthur; SELIGMANN-SILVA, Márcio (org.). Catástrofe e representação. São Paulo: Escuta, 2000. p. 185-205.

OLIVEIRA, Amurabi. Um balanço da discussão sobre ensino na Associação Brasileira de Antropologia. Cadernos da Associação Brasileira de Ensino de Ciências Sociais, [s.l.], v. 1, n. 1, p. 80-91, 2017.

SOARES, Luis Eduardo. O rigor da indisciplina: ensaios de antropologia interpretativa. Rio de Janeiro: Relume Dumará/Iser, 1994.

VEGA SANABRIA, Guillermo. O ensino de antropologia no Brasil: um estudo sobre as formas institucionalizadas de transmissão da cultura. 2005. 113p. Dissertação (Mestrado) Universidade Federal de Santa Catarina, Florianópolis, 2005.

VEGA SANABRIA, Guillermo; DUARTE, Luis Fernando Dias. O ensino de antropologia e a formação de antropólogos no Brasil hoje: de tema primordial a campo (possível) de pesquisa (antropológica). BIB - Revista Brasileira de Informação Bibliográfica em Ciências Sociais, São Paulo, n. 90, p. 1-32, setembro de 2019.

WAGNER, Roy. A invenção da cultura. Rio de Janeiro: Cosac Naify, 2010.

\section{Sônia Weidner Maluf}

Professora Titular da Universidade Federal de Santa Catarina, docente do Programa de Pós-Graduação em Antropologia Social e Professora Visitante no Programa de Pós-Graduação em Antropologia, Universidade Federal da Paraíba - João Pessoa (PB), Brasil. As principais áreas de atuação são em antropologia urbana e antropologia do contemporâneo, atuando principalmente nos seguintes temas: pessoa, indivíduo e sujeitos contemporâneos, antropologia política, Estado e políticas públicas, gênero e teorias feministas, corpo, saúde, saúde mental, religiosidades brasileiras. Coordena o Núcleo de Antropologia do Contemporâneo (http://transes.paginas.ufsc.br/) e é Coordenadora Executiva do Instituto Brasil Plural/INCT/CNPq (brasilplural.paginas.ufsc.br).

Endereço profissional: Programa de Pós-Graduação em Antropologia Social, Centro de Filosofia e Ciências Humanas, Bloco E, $4^{\circ}$ Andar. Universidade Federal de Santa Catarina (UFSC), Campus Reitor João David Ferreira Lima, Caixa Postal 476, Trindade, Florianópolis, SC. CEP: 88040-900.

E-mail: soniawmaluf@gmail.com

ORCID: https://orcid.org/0000-0002-9222-4348

\section{Como referenciar este artigo:}

MALUF, Sônia Weidner. Ensinar Antropologia em Tempos Sombrios. Ilha - Revista de Antropologia, Florianópolis, v. 24, n. 1, e80190, p. 117-134, janeiro de 2022. 